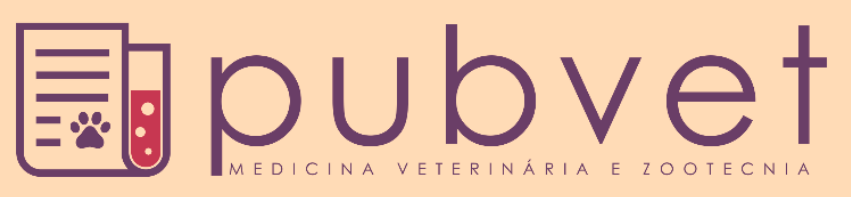

https://doi.org/10.31533/pubvet.v15n04a795.1-5

\title{
Anemia infecciosa em felinos: Relato de caso
}

\author{
Adriano Quirino da Silva1, Bruno Roque Lima ${ }^{2}{ }^{-9}$, Alexandre Fakih Cascardi ${ }^{3}$, *6 \\ ${ }^{1}$ Médico Veterinário, Pós graduando Clínica Médica de Pequenos Animais (Anclivepa - Sp). \\ ${ }^{2}$ Médico Veterinário, Doutorado em Centro Internacional de Pesquisa pelo AC Camargo Cancer Center, Brasil. \\ ${ }^{3}$ Médico Veterinário, Pós graduado em Clínica de Pequenos Animais, FMVZ (USP). \\ *Autor para correspondência,E-mail: casadosbichos@hotmail.com
}

Resumo. A anemia infecciosa em felinos é uma patologia causada por uma bactéria que tem como objetivo a destruição dos eritrócitos, causando vários sintomas e sinais clínicos como hiporexia, perda de peso, icterícia, colúria, pirexia entre outros. Um felino sem raça definida, macho, 3 anos de idade, foi atendido na Clínica Veterinária Casa dos Bichos, Santos, São Paulo, com queixa principal de hiporexia e perda de peso a cerca de cinco dias. Ao exame físico, verificou-se mucosas ictéricas e com tempo de preenchimento capilar em cinco segundos, turgor cutâneo diminuído, linfonodos sem alteração durante a palpação, temperatura corpórea $39,4^{\circ} \mathrm{C}$. A avaliação hematológica foi observada anemia e presença de Mycoplasma haemofelis. O ultrassom abdominal com esplenomegalia acentuada. A terapia antimicrobiana foi prescrita com hiclato de doxiciclina $5 \mathrm{mg} / \mathrm{kg}$; a cada 12 horas $/ 30$ dias. Por se tratar de uma patologia pouco identificada na rotina, exames hematológicos devem ser inclusos aos pacientes felinos para um diagnóstico e tratamento mais breve.

Palavras-chave: anemia infecciosa em felinos, Mycoplasmose haemofelis, icterícia, anorexia

\section{Infectious anemia in felines: Case report}

Abstract. Infectious anemia in felines is a pathology caused by a bacterium that aims to destroy erythrocytes causing various symptoms and clinical signs such as hyporexia, weight loss, jaundice, choluria, pyrexia, among others. A 3-year-old mixed breed male cat was seen at the Casa dos Bichos Veterinary Clinic, Santos, São Paulo, with a major complaint of hyporexia and weight loss about five days ago. Physical examination revealed jaundiced mucous membranes with a capillary filling time of five seconds, decreased skin turgor, lymph nodes unchanged during palpation, body temperature $39.4^{\circ} \mathrm{C}$. The hematological evaluation was observed anemia and the presence of Mycoplasma haemofelis. Abdominal ultrasound with marked splenomegaly. Antimicrobial therapy was prescribed with $5 \mathrm{mg} / \mathrm{kg}$ doxycycline hydrate; every 12 hours/30 days. As it is a pathology little identified in the routine, routine hematological exams should be included for feline patients for a brief diagnosis and treatment.

Keywords: feline infectious anemia, haemophilia mycoplasmosis, jaundice, anorexia

\section{Anemia infecciosa en felinos: Reporte de caso}

Resumen. La anemia infecciosa en felinos es una patología provocada por una bacteria que tiene como objetivo destruir los eritrocitos provocando diversos síntomas y signos clínicos como hiporexia, adelgazamiento, ictericia, coluria, pirexia, entre otros. Un gato macho de raza mixta de 3 años fue visto en la Clínica Veterinaria Casa dos Bichos, Santos, São Paulo, con una queja importante de hiporexia y pérdida de peso hace unos cinco días. El examen físico reveló membranas mucosas ictéricas con tiempo de llenado capilar de cinco 
segundos, disminución de la turgencia cutánea, ganglios sin cambios durante la palpación, temperatura corporal $39,4^{\circ}$. En la evaluación hematológica se observó anemia y presencia de Mycoplasma haemofelis. Ecografía abdominal con marcada esplenomegalia. Se prescribió tratamiento antimicrobiano con $5 \mathrm{mg} / \mathrm{kg}$ de hidrato de doxiciclina; cada 12 horas/30 días. Al tratarse de una patología poco identificada en la rutina, se deben incluir exámenes hematológicos de rutina en pacientes felinos para un diagnóstico y tratamiento más breve.

Palabras clave: anemia infecciosa felina, hemofilia micoplasmosis, ictericia, anorexia

\section{Introdução}

A anemia infeciosa felina é causada por um parasita microscópico, esse parasita causa doença infecciosa que tem afinidade por eritrócitos dos vertebrados (Jericó et al., 2015; Messick, 2004). Apesar de sua alta prevalência muitos se tornam portador assintomáticos além deste ser o único patógeno causar de anemia de forma primária nos felinos (Urquhart, 1996).

Os felinos acometidos pelo Mycoplasma haemofelis os felinos ficam com reservatório desta afecção ficando assim de uma forma comensal em felinos hígidos devido uma infecção aguda ou por um evento de imunossupressão ou cursa uma outra patologia (Harvey, 1988).

Se caso a infecção pela Mycoplasma haemofelis não for diagnosticada e tratada pode levar o paciente ao óbito, o seu diagnóstico pode ser realizado por esfregaço sanguíneo ou PCR (Braga et al., 2012; Messick, 2004; Foley et al., 1998; Berent et al., 1998).

Com sinais inespecíficos, os relatos mais comum dos gatos infectados são: anorexia, pirexia, letargia, hematúria, uveíte, perda de peso entre outras (Braga et al., 2012; Messick, 2004; Foley et al., 1998; Berent et al., 1998).

A prevalência pode ser em qualquer idade em ambos os sexos, mais a maior casuística é em gatos jovem e machos entre um e três anos e não castrados. A morbidade e a letalidade desta doença é baixa com ressalvas em pacientes imunossuprimidos e esplenectomizados (Sykes et al., 2008; Chandler \& Hilbery, 1998). O prognóstico é favorável desde que o paciente tenha identificação e tratamento precoce (Tanemo \& Sacco, 2009).

\section{Relato de caso}

Um felino sem raça definida, macho, 3 anos, não castrado, foi atendido na Clínica Veterinária Casa dos Bichos, Santos, São Paulo, com queixa principal de hiporexia e perda de peso havia cinco dias. Segundo relato da tutora, o paciente logo após o quinto dia além dos sinais anteriormente relatado, apresentou quadro de icterícia cutânea, quando então decidiu procurar o atendimento clínico para o felino.

O paciente segundo a tutora apresentava anorexia, polidipsia, colúria, porém com o volume normal, aquesia e êmese.

A tutora nega puliciose ou ixididiose, porém relata que não faz nenhum tipo de controle para ectoparasitas e não costuma realizar nenhum tipo de inspeção; paciente não imunizado com nenhuma vacina, estando com a vermifugação em dia. Paciente tem acesso a rua, alimentação seca e úmida de qualidade "Premium" e acesso a água da rede pública.

Inspeção do paciente realizada em ambiente tranquilo sem interferências externas, o paciente estava alerta, mas em decúbito lateral e segundo a tutora atitude não atípica do paciente.

Ao exame físico, o felino apresentava mucosas ictéricas e com tempo de preenchimento capilar em cinco segundos, turgor cutâneo diminuído, linfonodos sem alteração durante a palpação, temperatura corpórea $39,4^{\circ} \mathrm{C}$, com a frequência respiratória e cardíaca dentro dos valores normais de referência.

Na palpação trans abdominal o paciente não teve nenhum desconforto, mas foi observado aumento significativo de alguma estrutura que parecia ser fígado ou baço. 
O exame oftálmico revelou esclera totalmente ictérica (Figura 1), realizado os testes oftálmicos de rotina ambulatorial com teste de fluoresceína negativo, o paciente apresentava também a mucosa oral igualmente ictérica (Figura 2). Durante inspeção do paciente foi observada que estava com toda a extensão cutânea ictérica (Figura 3).

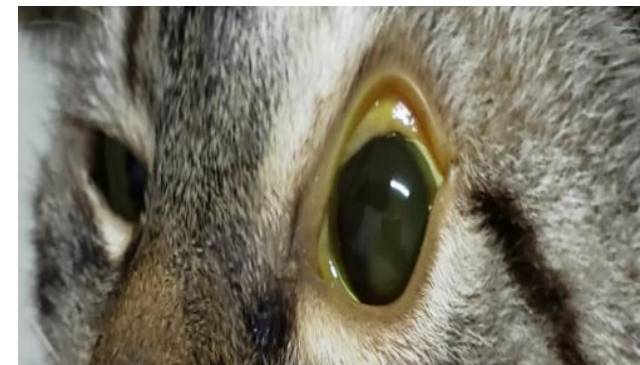

Figura 1. Mucosa ocular ictérica.

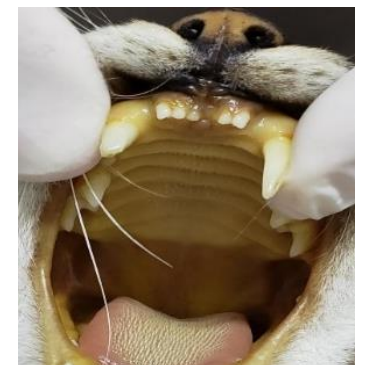

Figura 2. Mucosa oral icterica.

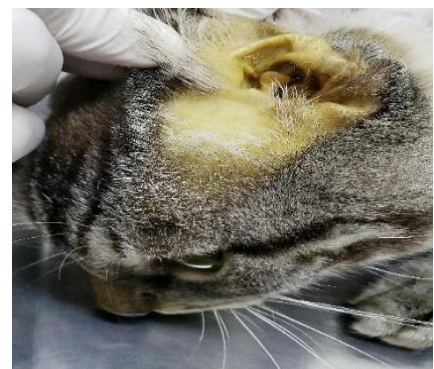

Figura 3. Extensão cutânea ictérica.

Foram solicitados exames laboratoriais hematológicos de hemograma, leucograma, contagem de plaquetas, e bioquímicos de bilirrubina total e frações, albumina, creatinina, fosfatase alcalina (FA), gama glutamil transferase (GGT), globulina, proteínas totais, aspartato aminotransferase (AST), alanina aminotransferase (ALT), ureia, urina I; e de imagem o ultrassom abdominal.

As alterações reveladas pelos exames solicitados foram exames hematológicos: anemia com eritrócitos 3,2 (5,0 - $\left.10 \times 10^{6} / \mathrm{ul}\right)$, hemaglobina $6,3 \mathrm{~g} / \mathrm{dL}(8,0-15,0 \mathrm{~g} / \mathrm{dL})$, hematócrito $19 \%(24-45 \%)$ no esfregaço sanguíneo foram observados eritroblastos $9 / 100$, leucócitos, anisocitose de hemácias ++-, policromasia ++-, presença de Mycoplasma haemofelis +-- (Figura 4).

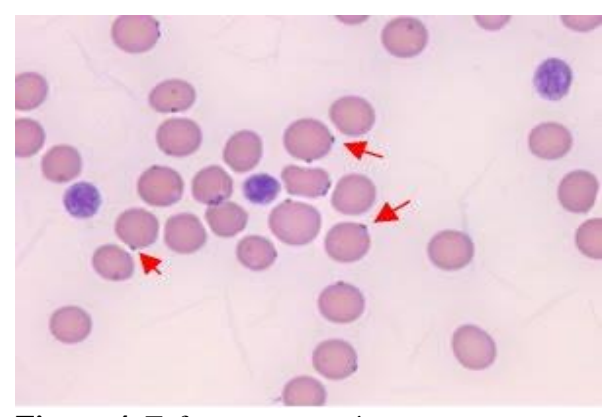

Figura 4. Esfregaço sanguíneo.

No leucograma foi observado eosinofilia 1.456/ul ( 0 - 1.250/ul), em plaquetograma trombocitopenia 120.000/ul (200.000 - 500.000/ul) descrito pelo patologista plasma ictérico +++.

Os resultados bioquímicos foram observados alterações em: bilirrubina total $28,93 \mathrm{mg} / \mathrm{dL}(0,10-$ $0,6 \mathrm{~g} / \mathrm{dL})$, bilirrubina direta $17,12 \mathrm{mg} / \mathrm{dL}(0,06-0,3 \mathrm{mg} / \mathrm{dL})$, bilirrubina indireta $11,81 \mathrm{mg} / \mathrm{dL}(0,01-$ $0,5 \mathrm{mg} / \mathrm{dL}$ ), alanina aminotransferase (ALT) 152 U.I./L (10 - 88 U.I./L) os outros parâmetros bioquímicos solicitados estavam dentro dos valores de referência.

Após coleta da urina por cistocentese no momento do exame de ultrassom abdominal, foi realizada a urinálise, sendo avaliado no exame físico da amostra o aspecto turvo (límpido/ligeiramente turvo), coloração acastanhada (amarelo citrino) e odor amoniacal (sui generis). Ao exame químico da urina bilirrubina +++ (negativo), proteína +-- (negativo), sangue oculto +++ (negativo) e urobilinogênio anormal (negativo) e finalmente o exame de sedimento cristais bilirrubina +++ (ausentes).

No exame de ultrassom abdominal, foram relatadas as seguintes alterações: fígado com dimensões normais, porém com acentuada redução difusa de ecogenicidade, destacando paredes vasculares imagem inclui processo inflamatório agudo/toxêmico nos diferenciais (Anexo 1).

Vesícula biliar repleta por conteúdo anecogênico, com pequena porção ecogênica entremeada discreta lama biliar / (colangite). Baço com dimensões acentuadamente aumentada (esplenomegalia acentuada). As outras estruturas avaliadas tiveram o resultado nada digno de nota. 
Com os resultados dos exames solicitados juntamente com a tutora, foi recomendado a realização de outros exames complementares para um diagnóstico mais fidedigno que seriam o PCR para micoplasmose e FIV/FELV, porém por motivos pessoais os exames não foram autorizados para a sua execução e então foi preconizado a conduta terapêutica com base nos dados coletados pelos exames realizados e pelo histórico clínico do paciente.

O tratamento prescrito foi: uso oral com antibioticoterapia a base de hiclato de doxiciclina $5 \mathrm{mg} / \mathrm{kg}$ a cada doze horas, pelo período de trinta dias seguidos.

Como forma complementar ao tratamento, foi prescrito polivitamínico oral, com o objetivo de suplementação e estimulação do apetite e aplicação de preventivo contra puliciose por via tópica.

Após a adesão imediata da tutora ao tratamento terapêutico, foi agendado o retorno do paciente para reavaliação no término da administração dos fármacos, junto ao estabelecimento veterinário para avaliação da conduta.

Conforme previamente agendado, a tutora veio ao retorno com o paciente e segundo seu relato, o paciente estava em ótimas condições, voltando as suas atividades rotineiras além de alimentação e hidratação.

Ao exame físico, pode-se observar que a coloração de todas as mucosas voltaram ao padrão fisiológico (Figuras 5, 6 e 7), e teve ganho de peso de oitocentos e cinquenta gramas em relação ao dia do atendimento.
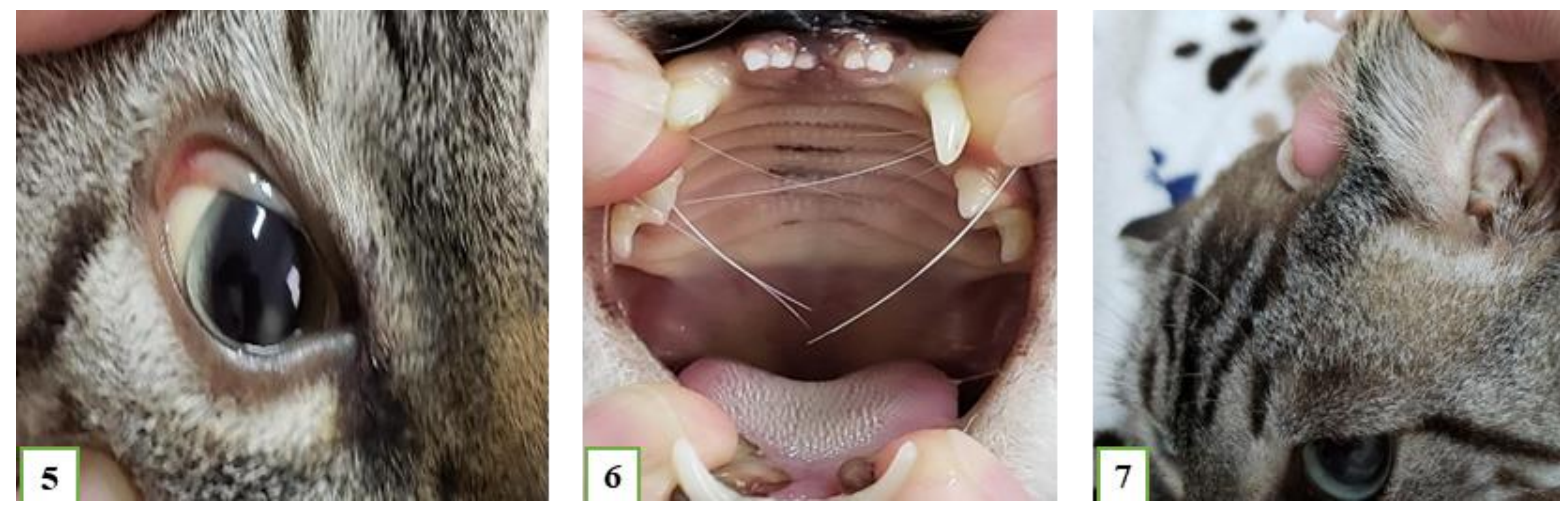

Figuras 5, 6, 7. Evolução do paciente após o tratamento. Mucosa ocular (5), Mucosa oral (6) e Extensão cutânea (7)

Portanto a conduta adotada junto dos exames solicitados e com o tratamento realizado que conferem com a literatura consultada o resultado para o paciente foi positivo.

\section{Resultados e discussão}

No presente relato, o paciente acometido um felino sem raça definida, macho, 3 anos, não castrado, condiz com os relatos da literatura (Sykes et al., 2008; Chandler \& Hilbery, 1998). A anemia hemolítica dos felinos é uma patologia de grande importância na rotina clínica pelas suas consequências, porém devido aos baixos índices de dados epidemiológicos descritos na literatura, os dados atuais devem estar bem abaixo dos pacientes contaminados.

Apesar dos avanços para o diagnóstico preciso com a implementação do exame molecular de Reação em Cadeia pela Polimerase (PCR), a adesão dos tutores ainda é baixa dependendo da região de atuação, ficando assim o diagnóstico com base nos dados coletados na anamnese, sinais clínicos e exames laboratoriais hematológicos, equivalente com a literatura (Braga et al., 2012; Messick, 2004; Foley et al., 1998; Berent et al., 1998).

Os sinais clínicos são variáveis dependo do estágio que o paciente está cursando a doença, sendo que nas fases agudo ou crônica se observa grande variação de sinais clínicos e alterações dos exames solicitados; no paciente atendido os sinais clínicos foram compatíveis com a literatura, (Braga et al., 2012; Messick, 2004; Foley et al., 1998; Berent et al., 1998). Entre os sinais clínicos apresentados pelo 
paciente, a anorexia, colúria e letargia são os sinais observados inicialmente relatados pelos tutores seguidos de icterícia.

Relatos de Braga et al. (2012) conforme o estágio da anemia é detectado e o tratamento iniciado a melhora clínica do paciente é bem satisfatória, tornando assim a patologia com um bom prognóstico, no presente relato de caso o diagnóstico foi fechado com o esfregaço sanguíneo.

O tratamento é realizado a base de antibiótico, que segundo a literatura, o hiclato de doxiciclina com dose $5 \mathrm{mg} / \mathrm{kg}$ a cada doze horas por um período de quatro semanas, apresenta boa resposta terapêutica, como foi no paciente do relato de caso, estando de acordo com os relatos de Jones (2000) e Thrall (2015).

A anemia infecciosa dos felinos tem potencial zoonótico relatado pela literatura, tornando a manipulação de sangue e materiais de paciente infectados um momento de muita cautela, principalmente para os médicos veterinários e patologistas clínicos, porém para os felinos infectados tem um bom prognóstico desde que o paciente tenha uma identificação e tratamento precoce como foi observado no paciente tratado sendo equivalente a literatura (Tanemo \& Sacco, 2009).

\section{Conclusão}

O respectivo relato demostra a importância do diagnóstico precoce, pois a anemia infecciosa dos felinos é progressiva se não for tratada, podendo levar o paciente ao óbito e essa conduta aplicada aumenta as chances de sucesso no tratamento.

\section{Referências}

Berent L.M., Messick J.B. \& Cooper S.K. (1998). Detection of Haemobartonella felis in cats with experimentally induced acute and chronic infections, using a polymerase chain reaction assay. American Journal of Veterinary Research, 59:1215- 1220.

Braga, M. S. C. O., André, M. R., Freschi, C. R., Teixeira, M. C. A., \& Machado, R. Z. (2012). Molecular detection of hemoplasma infection among cats from São Luís island, Maranhão, Brazil. Brazilian Journal of Microbiology, 43(2), 569-575. https://doi.org/10.1590/S1517-83822012000200018

Chandler, E. A. \& Hilbery, A. D. R. \& Gaskell, C. J. Medicina e terapêutica de felinos. São Paulo: Manole, 1988 (1988). Medicina e Terapêutica de Felinos. São Paulo: Manole.

Foley, J. E., Harrus, S., Poland, A., Chomel, B. \& Pedersen, N. C. (1998). Molecular, clinical, and pathologic comparison of two distinct strains of Haemobartonella felis in domestic cats. American Journal of Veterinary Research, 59(12): 1581-1588. PMid:9858411.

Jericó, M. M., Kogika, M. M., \& Andrade Neto, J. P. (2015). Tratado de medicina interna de cães e gatos. Guanabara Koogan.

Jones, T. C. (2000). Patologia veterinária (p. 410). $6^{a}$ Edição. Barueri: Manole

Messick, J. B. (2004). Hemotrophic mycoplasmas (hemoplasmas): a review and new insights into pathogenic potential. Veterinary Clinical Pathology, 33(1), 2-13. https://doi.org/10.1111/j.1939165X.2004.tb00342.X

Sykes, J. E., Terry, J. C., Lindsay, L. L., \& Owens, S. D. (2008). Prevalences of various hemoplasma species among cats in the United States with possible hemoplasmosis. Journal of the American Veterinary Medical Association, 232(3), 372-379. https://doi.org/10.2460/javma.232.3.372

Taneno, J. C. \& Sacco, S. R. (2009). Micoplasmose felina - Relato de caso. Revista Científica Eletrônica de Medicina Veterinária, 12, 34-40.

Thrall, M. A. (2015). Hematologia e Bioquímica Clínica Veterinária. In 2. ed. Editora Roca.

Urquhart, G. M. (1996). Parasitologia veterinária (2nd ed.). Guanabara Koogan.

\section{Histórico do artigo:}

Recebido: 27 de outubro de 2020.

Aprovado: 12 de novembro de 2020

Disponível online: 16 de março de 2021.
Licenciamento: Este artigo é publicado na modalidade Acesso Aberto sob a licença Creative Commons Atribuição 4.0 (CC-BY 4.0), a qual permite uso irrestrito, distribuição, reprodução em qualquer meio, desde que o autor e a fonte sejam devidamente creditados.

\section{Anexo 1}




\title{
IMAGEM VETERINÁRIA
}

$\mathrm{N}^{\circ} \mathrm{OS}: \mathbf{1 5 6 3 3 0 1 7 9 1 7 3 7}$

Espécie: FELINO
Paciente: MARROM

Raça: SRD
Data: 16/07/2019

\section{Sexo: $\mathbf{M}$}

\author{
Idade: 3 ano(s), 1 mes(es), 25 dia(s) \\ Med. Vet. Solicitante: ADRIANO QUIRINO \\ Clínica: Omega
}

Responsável:

\section{RELATÓRIO ULTRASSONOGRÁFICO}

Fígado com dimen sões normais em relação aos limites do gradil costal, parênquima hom ogên eo, contornos regulares, bordas finas, porém acentuada redução difusa da ecogenicidade destacando paredes vasculares - imagem inclui processo inflamatório agudo / toxêmico nos diferenciais. Arquitetura vascular com calibre e trajeto preservados. Vesícula biliar repleta por conteúdo an ecogênico, com pequen a porção ecogên ica entrem eada (discreta lama biliar - achado incomum para a espécie em estudo, podendo estar relacionado a colangite), paredes finas.

Discreta dilatação em ducto biliar comum medindo $0,25 \mathrm{~cm}$ de diâm etro, sem evidências son ográficas da presença de litíases nem processos obstrutivos - colangite. Papila duodenal maior dilatada, medindo $\mathbf{0 , 4 4} \mathbf{c m}$ sem evidências de processos obstrutivos.Vias intra-hepáticas sem evidên cias de dilatações.

Baço com dimensões acentuadam ente aum entadas (es plenomegalia acent uada), contornos regulares, ecotextura finam ente grosseira e ecogenicidade habitual - diferencial para: processo infeccioso / inflamatório.

Pâncreas com dimensões evidentem ente aumentadas medindo $\mathbf{1 , 1 5} \mathbf{c m}$ em lobo direit o; $1,14 \mathrm{~cm}$ em lobo es querdo e $\mathbf{1 , 2 4 c m}$ em corpo ( $n$ ormal até: $0,44 \mathrm{~cm} ; 0,58 \mathrm{~cm}$ e $0,63 \mathrm{~cm}$ respectivam ente), com ecotextura finam ente grosseira e ecogenicidade evidentem ente reduzida, ain da se observa dilatação em ducto pancreático m edindo $0,14 \mathrm{~cm}$ de diâm etro ( $\mathrm{n}$ ormal até $0,10 \mathrm{~cm}$ ) e aum en to da ecogenicidade em gordura mesentérica peri-pancreática - compatível com pancreatopatia inflamatória junto a esteatite adjacente.

Rins simétricos (RD: 4,05 cm e RE: 4,48cm) com contornos regulares, arquitetura preservada, defin ições corticom edulares mantidas, porém evidente aum ento da ecogen icidade nas corticais - fisiológico para a espécie em estudo em virtude ao acúmulo adiposo em túbulos renais, porém considerar nefropatia como diferencial caso haja suspeita clínica. Não há sin ais de hidron efrose.

Estôm ago pou co repleto por con teú do pastoso (restos alim entares), paredes finas m edin do 0,26cm, com estratificação parietal mantida. Alças intestinais repletas por conteú do gasoso, mu coso e fecal, paredes finas (du oden o: 0,22cm; íleo: 0,26cm; cól on ascen dente: $0,13 \mathrm{~cm}$ ) peristaltismo evolutivo e uniforme, sem evidência de alterações.

Testículos simétricos, com linhas mediastinais preservadas, ecotextura e ecogenicidade dentro da normalidade.

Adrenal esquerda e direita visibilizadas, dimensões normais medin do respectivam ente $0,39 \mathrm{~cm} \times 1,10 \mathrm{~cm}$ e $0,43 \mathrm{~cm} \times 1,10 \mathrm{~cm}$ (espessura $x$ com prim ento), hipoecogênicas e com ecotextura preservada.

\section{Assinado eletronicamente por: CRMV-SP 24.932 - MSC. M. V. CAROLINE C. T. AUGUSTO ROQUE}




\section{IMAGEM VETERINÁRIA}

$\mathrm{N}^{\circ} \mathrm{OS}: 1563301791737$

Espécie: FELINO
Paciente: MARROM

Raça: SRD
Data: 16/07/2019

Sexo: $\mathbf{M}$

Idade: 3 ano(s), 1 mes(es), 25 dia(s)

Responsável:

Med. Vet. Solicitante: ADRIANO QUIRINO

Clínica: Omega

Ausên cia de líquido livre e linfonodom egalia abdominal. Veia cava inferior e aorta de calibre e trajetos preservados.

Bexiga urinária com boa repleção, de aspecto piriforme, preenchida por conteú do an ecogênico com discretos ecos puntiform es em su spen são (sedimentos - cristalúria / alta celularidade / partículas de gordura), paredes fin as e ecogên icas m edin do 0,10cm de espessura, margens internas lisas.

Assinado el etronicamente por: CRM V-SP 24.932 - MSC. M. V. CAROLINE C. T. AUGUSTO ROQUE

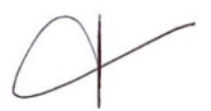

